\title{
Ámbitos dinámicos. De cómo la tectónica cede paso a los agenciamientos
}

\author{
María Verónica Machado Penso ${ }^{1} \mid$ Edward Pérez-González ${ }^{2} \mid$ Jorge Aldea ${ }^{3}$
}

Recibido: 14/05/2019 | en su versión final: 11/01/2020

Resumen

\begin{abstract}
A partir de una perspectiva dinámica de la realidad surge esta investigación, cuyo propósito es determinar cómo la tectónica del espacio arquitectónico cede paso a los procesos espaciales que, imprimen características dinámicas a la arquitectura. El desarrollo del objetivo de la investigación se inicia con una búsqueda documental que hace seguimiento al concepto de tectónica en la arquitectura desde su etimología y sus aplicaciones en realidad contemporánea. Esta indagación sirve como marco de referencia al estudio de casos, que permiten identificar en esas arquitecturas, las características dinámicas debidas a los agenciamientos. Tras el análisis de los casos, en relación con las condiciones que revelan las posturas sobre la realidad contemporánea, se evidencia como las tectónicas ceden paso ante agentes que toman el control de determinados componentes tectónicos, y como la producción de la obra de arquitectura queda bajo condiciones de procesos emergentes. Es así como estas arquitecturas evidencian indeterminación, inestabilidad, incertidumbre, deformación, ambivalencia, procesos y/o emergencia en su constitución. Acciones que apuntan a la generación de una arquitectura cuya tectónica da cabida a los agenciamientos que, permiten desde un abordaje interdisciplinario, permear otros procesos, experiencias y efectos en la arquitectura. La aportación de este artículo está en incursionar sobre otro modo de comprender la arquitectura que, comienza a salirse de los preceptos tectónicos para sumergirse en ámbitos dinámicos, otorgándole a la arquitectura condiciones indeterminadas, inestables, imprecisas, deformables, ambivalentes, procesales y emergentes.
\end{abstract}

Palabras clave: Arquitectura contemporánea; tectónica; dinámicas

Citación

Machado, M. V. et al. (2020). Ámbitos dinámicos. De cómo la tectónica cede paso a los agenciamientos, ACE: Architecture, City and Environment, 14(42), 8288. DOl: http://dx.doi.org/10.5821/ace.14.42.8288

1 Doctora, Arquitecta, Departamento de Arquitectura y Diseño, Universidad de la Costa, Barranquilla, Colombia (ORCID ID: 0000-0001-8727-3666, Researcher ID: K-7948-2018), 2 Doctor, Ingeniero Civil, Universidade Federal de Pelotas, Rio Grande do Sul, Brasil (ORCID ID: 0000-0002-5215-8681), ${ }^{3}$ M.Sc., Arquitecto, Departamento de Arquitectura y Diseño, Universidad de Zulia, Maracaibo, Venezuela (ORCID ID: 0000-0002-0382-8888). Correo de contacto: mmpenso@hotmail.com

ACE, 14 (4.2) CC BY-ND 3.0 ES | UPC Barcelona, España | Ámbitos dinámicos. De cómo la tectónica cede paso a los 1 agenciamientos. DOI: http://dx.doi.org/10.5821/ace.14.42.8288 


\section{Dynamic scopes. How tectonics gives way to the agencements}

Abstract

From a dynamic perspective of reality, this research aimes to determine how tectonics of architectural space gives way to spatial processes that give dynamic characteristics to architecture. This research begins with a reference documentation that tracks the concept of tectonics in architecture from its etymology and its applications in contemporary reality. This study serves as a frame of reference for the study of cases, which allow to identify -in those architectures- the dynamic characteristics due to the agencements. After the analysis of cases, in relation to the conditions revealed by the positions on contemporary reality, it is evident how tectonics give way to agents that take control of certain tectonic components, and how the production of the architectural work is under emerging-process conditions. Thus, these architectures show indeterminacy, instability, uncertainty, deformation, ambivalence, processes and/or emergency in their constitution. Actions that point to the generation of an architecture whose tectonics accommodate agencements that allow, from an interdisciplinary approach, to permeate other processes, experiences and effects on architecture. The contribution of this article is to venture into a different way of understanding architecture that begins to break out with tectonic precepts to immerse itself in dynamic fields, granting to architecture indeterminate, unstable, imprecise, deformable, ambivalent, procedural and emerging conditions.

Keywords: Contemporary architecture; tectonics; dynamics

\section{Introducción: La tectónica y estereotomía}

La concepción tectónica de la arquitectura le es inherente desde sus orígenes etimológicos. Y es que arquitectura y arquitecto devienen del griego architékton, compuesto por archi "ser el primero" y tékton "obrero, carpintero", a su vez tékton deviene del tíktein que significa "producir, dar a luz" (Corominas, 1985). El término tékton está relacionado con la raíz indoeuropea teks vinculada con el verbo latino texere, que significa tejer. (Anders, et al, 2018). Tejer como juntar, como el trenzar estructuras (Azara, 2005), que desde la labor del arquitecto erige la arquitectura. Por otra parte, la estereotomía es una palabra compuesta que deviene etimológicamente del griego stereós "sólido, duro, robusto" y témnein "cortar" (Corominas, 1985a) extirpar (Anders, et al, 2010-2019). Involucra las técnicas para el corte y talla de materiales densos y pesados y apilables.

Karl Otfried Müller (Azpiazu, 2013) es quien introduce el concepto de tectónica en la teoría del arte a partir de su definición etimológica, refiriéndose a ella como una serie de artes que elaboraran desde muebles hasta lugares, y que encuentra su clímax en la arquitectura, donde se libera del requerimiento para entregarse a la expresividad de las emociones. Posición que reúne la funcionalidad constructiva con la poética. Para Bötticher, en el primer tomo de la Tectónica de los Helenos (Azpiazu, J., 2013), la tectónica es una construcción que permite "permear éticamente" (Bötticher, 1852 en Azpaziu, 2013) la vida emocional y corporal, yendo más allá de lo meramente constructivo. Rudolf Redtenbatcher, define tectónica como "el arte de producir espacios en los que se habita, la arquitectura en sentido amplio” (Redtenbatcher, 1883 en Azpiazu, 2013). Tres posiciones que asumen la tectónica más allá de la técnica y la conjugan con el arte y la ética. 
A pesar de que se han encontrado en archivos enfoques de Gottfried Semper sobre la tectónica ligados y casi textuales a las posiciones de Müller y Bötticher (Azpaziu, 2013), en su libro, "El estilo en las artes técnicas y tectónicas o estética práctica. Manual para técnicos, artistas y amantes del arte”, utiliza la tectónica como "denominación de la clase técnica de la carpintería" (Semper, 1860 en Azpiazu, 2013, pág. 57), dejando a un lado los desarrollos del concepto dado por Müller y Bötticher y concediendo el arte, al producir técnico y no lo que alberga su constitución de lo ya construido. Semper (Azpiazu, 2013) al inicio del capítulo siete, del libro El Estilo, se refiere a la tectónica como:

"El arte de ensamble de partes rígidas de forma de barra en un sistema en sí mismo indeformable es indiscutiblemente el más importante de todos para la teoría del estilo monumental (...) Mientras que el armazón de carpintería presenta entonces el modelo más generalizado y elevado de la arquitectura" (Semper, 1860 en Azpiazu, 2013, pág. 643)

La tectónica es aquí referida como una técnica que deviene del arte de ensamblar. El arte de juntar, articular, tejer, entramar barras duras para conformar un armazón. Armazón estable, estático, que no perderá la integridad de su forma. Y al ser la técnica más importante, según Semper, aplicada en la construcción de monumentos, por correspondencia, serán perdurables. Ya que uno de sus propósitos (Semper, 1860 En Azpiazu, 2013, pág. 643), es la conformación de la estructura de un esqueleto, construido tanto para un mueble como para un edificio inamovible.

La tectónica, según Semper además de abarcar los armazones de madera de los techos y de las columnas que los soportan, comprende el campo del mobiliario, una parte de la construcción en piedra y un sistema de la construcción en metal. Por otra parte, la estereotomía abarca mampostería, movimiento de tierra, el mosaico y la talla (Semper, 1860 en Azpiazu, 2013).

Posterior a Semper quien retoma el concepto de tectónica, en términos etimológicos, conceptuales, constructivos y poéticos en la arquitectura, es Kenneth Frampton (1999a), ya que Seker y Collins lo hacen más en un ámbito epistemológico: el primero en referencia a establecer una nueva rama del conocimiento y el segundo como un concepto en diferencia al de construcción y estructura que relacionará la fuerza y la forma (Semper, 1860 en Azpaziu, 2013)

En la introducción del libro "Estudios sobre cultura tectónica" (Frampton, 1999a) desde la indagación de los orígenes del concepto de tectónica lo relaciona con la habilidad técnica del carpintero y encuentra que, en la obra de Safo, al carpintero se le nombra poeta. Por otra parte, destaca a partir de los estudios filológicos del término realizados por Adolf Heinrich Borbein en 1982, que el concepto de tectónica tiene un sentido más estético que técnico en el producir de la obra, aspecto que ya evidenciaba, el texto aquí citado de Semper sobre la tectónica, en el cual se refiere a esta como arte.

Frampton afirma que a partir de la clasificación de los cuatro elementos de la arquitectura, que hiciera Semper en su texto homónimo (2014), divide las técnicas de la edificación en dos procedimientos fundamentales: "la tectónica de la estructura, donde los ligeros componentes lineales están ensamblados como si abarcaran una matriz espacial y la estereotomía del basamento, donde masa y volumen se forman conjuntamente mediante el apilamiento repetido de los elementos más pesados" (Frampton, 1999, pág. 16). Sin embargo, en ese texto de Semper no aparece la división como la señala Frampton, sino que, a partir de los cuatro elementos: El hogar, el techo, el recinto y el terraplén, establece una relación con las habilidades técnicas del hombre para la construcción arquitectónica. Es así como, el hogar lo relaciona con la cerámica y la metalurgia, el techo con la carpintería, el recinto con el tejido y el terraplén con la albañilería y la hidráulica (Semper, 2014). Es en el libro El Estilo, publicado por primera vez en 1860, nueve años después del texto "Los cuatro elementos de la arquitectura”, que Semper dentro de la clasificación de las artes técnicas es que, incluye a la tectónica (carpintería) y a la estereotomía (mampostería, etc.) entre las cuatro clases que 
las definen (Semper, 2014). En otro orden de ideas, la interpretación de Frampton, de las definiciones de tectónico y estereotómico, encajan dentro de lo expresado por Semper para ambos términos.

Ahora bien, en Frampton (1990, pág. 31) "the tectonic lies suspended between a series of opposites, above all between the ontological and the representational. However, other dialogical conditions are involved in the articulation of tectonic form, particularly the contrast between the culture of the heavy-stereotomics, and the culture of the light-tectonics". Esta suspensión ha sido evidente desde la categorización que le refiriere a Semper.

Es desde esta tensión entre opuestos que se considera oportuno establecer el concepto de estereotomía en Semper, ya que es a partir de Frampton, como Alberto Campo Baeza y José María Aparicio Guisado, hacen uso de ambos conceptos como pares opuestos y complementarios

El campo de la estereotomía, una de las cuatro categorías de las artes técnicas para Semper, está definido por tareas técnicas que utilizan "materias primas que en razón de su constitución dura, compacta y homogénea ofrecen gran resistencia a la deformación y a la rotura por aplastamiento, y son entonces de significativa resistencia a la compresión; permiten mediante la remoción de partes de la masa elaborar cualquier forma deseada; y en piezas regulares pueden unirse para formar sistemas resistentes en las cuales la resistencia a compresión es el principio más importante de la estructura" (Semper, 1860 en Azpiazu, 2013, pág. 739).

Es una de las artes técnicas, por lo cual su producir es creador. Una creación que deviene de la extracción de partes del material en bruto y de su modelación singular. También, su procedimiento como corte genera materiales que pueden agruparse por apilamiento y trabajar estructuralmente en compresión conduciendo de forma continua las cargas hacia el suelo (Campo Baeza, 1999).

Alberto Campo Baeza (2003) se apropia de los conceptos de estereotómico y tectónico enunciados por Frampton (1999a) para comprender el hecho de que hay partes del edificio que pertenecen a la tierra y partes de ella que se separan y que dicha relación es producto de cómo la arquitectura dialoga con la gravedad y construye el espacio. De manera más específica, Campo Baeza (1999, pág. 60) entiende "[...] por arquitectura estereotómica aquella en la que la gravedad se transmite de una manera continua, en un sistema estructural continuo, donde la continuidad constructiva es completa. Es la arquitectura masiva, pétrea, pesante. La que se asienta sobre la tierra como si de ella naciera. Es la arquitectura que busca la luz, que perfora sus muros para que la luz entre en ella. Es la arquitectura del pódium, del basamento. La del estilóbato." La continuidad en la edificación y la transmisión de cargas es determinante para la concepción estereotómica de la arquitectura.

La arquitectura tectónica, por otra parte, la concibe como “[...] aquella en que la gravedad se transmite de una manera discontinua, en un sistema estructural con nudos donde la construcción es sincopada. Es la arquitectura ósea, leñosa, ligera. La que se posa sobre la tierra como alzándose sobre puntillas. Es la arquitectura que se defiende de la luz, que tiene que ir velando sus huecos para poder controlar la luz que la inunda. Es la arquitectura de la cáscara. La del ábaco”. (Campo Baeza, 1999, p. 60). En Campo Baeza la secuencia y la pauta en la transmisión de las cargas y la unión entre los elementos estructurales definen la tectónica. Es una arquitectura cuya estructura se va tramando en articulaciones.

Jesús María Aparicio Guisado expone que el desarrollo constructivo de la arquitectura, tanto en oriente como en occidente, se ha dado en torno a dos formas contrapuestas de aproximación: lo estereotómico y lo tectónico (Aparicio, 2000). La primera se fundamenta en horadar la masa pesante de la materia; mientras que la segunda se soporta en erigir y tejer la materia. Aborda este discurso primeramente desde la contraposición de ambas categorías, distinguiendo el carácter estereotómico

ACE, 14 (4.2) CC BY-ND 3.0 ES | UPC Barcelona, España | Ámbitos dinámicos. De cómo la tectónica cede paso a los 
de la cueva y tectónico de la cabaña (Aparicio, 2000). Sin embargo, a diferencia de los autores antes mencionados, este visualiza ciertas particularidades que viene a complementar esta lógica; en primer lugar, señala que lo estereotómico trabaja exclusivamente a compresión y es telúrico, gravitando hacia la tierra y encerrando el espacio en sí mismo, apartándolo del exterior; mientras lo tectónico descompone sus cargas en compresión y tensión y apunta hacia una desmaterialización del edificio hacia el cielo permitiendo un espacio fluido que relaciona interior y exterior. Aparicio no solo concibe el hecho, como sus predecesores, señala como una visión u otra son causa y/o consecuencia de culturas estáticas o nómadas; públicas o privadas, abiertas o cerradas.

Aparicio Guisado afirma que lo tectónico y estereotómico constituyen formas de pensamientos contrarias define lo estereotómico como "[...] una forma de pensamiento que incorpora lo universal en la arquitectura. Esta incorporación trasciende la naturaleza para convertirse en una sublimación de la idea. Ésta se convierte en protagonista de la arquitectura. La idea en la arquitectura estereotómica tiene forma y función propias de carácter universal." (Aparicio, 2000, pág. 190) Mientras lo tectónico incorpora la naturaleza a partir de la sublimación de la materia y esta se convierte, indistintamente del enfoque en protagonista de la idea en arquitectura.

Desde los conceptos de continuo y discontinuo el autor aborda la fragmentación y unidad del espacio y los componentes que lo definen. A través del análisis del Partenón el autor ejemplifica lo estereotómico afirmando que "La materia del muro estereotómico tiene un carácter pétreo, la materia natural que encierra en sí su construcción y que es sólida, presente, continua e inmutable en el tiempo. La idea de continuo hace que el muro estereotómico se relacione con la construcción in situ en un muro grueso, sólido y pesante ligado a la tierra [...]. El espacio de la arquitectura estereotómica se contempla en quietud, pues su total perfección hermética, geométrica y continua permite que sea entendido de esta manera." (Aparicio, 2000, pág. 17).

La casa Farnsworth, por otra parte, es utilizada para ejemplificar lo tectónico, pero que en la búsqueda de Mies por un espacio exento de estructura en su interior (Machado, 2013), se podría afirmar que éste es un ejemplo de tectónica de la modernidad, donde sólo interesa la plana continuidad de la masa horizontal y es el vacío entre ellos el que figuradamente lo mantiene en pie.

La revisión de los conceptos de tectónica y estereotomía en estos autores permite comprender cada uno de estos conceptos a partir de los cuales se pueden establecer las diferencias para definir, mediante los estudios de caso, la caracterización de los ámbitos dinámicos.

Es entonces que está investigación asume el concepto de tectónica como el arte de construir arquitectura mediante la conexión y articulación de componentes axiales que definen un edificio estable erigido con materiales resistentes, configurando formas estandarizadas y singulares que como arte pueden referir o no a una poética y en conjunción con el tiempo producen el espacio arquitectónico.

La estereotomía se comprende desde dos perspectivas, por un lado, la extracción y talla del material para que en su oquedad se defina el espacio del habitar por extracción y por otro lado constituye un sistema a través del cual se construye por apilamiento y empuje compensado entre de sus componentes constructivos. Su desempeño estructural es fundamentalmente a compresión.

De esta manera la tectónica y la estereotomía han construido a través del tiempo formas espaciales de la arquitectura que van desde geometrías euclidianas hasta geometrías fluidas y caóticas. En la arquitectura contemporánea existen posturas que desde la tectónica y/o la estereotomía, buscan otras formas de operar la arquitectura, posiciones que apuestan por: una noción de campo cuyo protagonismo está en las relaciones y no en la primacía del objeto (Montaner, J., 2008); una 
arquitectura como paisaje donde podría inscribirse la posición de arquitectura como geografía, de Manuel Gausa (2001); lo cambiante, lo mutable, impermanente, efímero, temporal que se evidencian en formas flexibles derivadas de la modernidad arquitectónica y las posibilidades de la planta libre (Le Corbusier en Benévolo, 2010); la fabricación digital y el diseño algorítmico que conduce hacia el mundo complejo en la arquitectura; el espectáculo y el consumo de la imagen, palpable en la arquitectura Bark Ingels Group (Ingels, 2009) ; la experimentación que busca lo transversal, desviado y alterado patente en las obras de Selgas Cano (Walker, 2014); la sensibilidad social y la política como las arquitecturas de Santiago Cirugeda a través de sus recetas urbanas (2007) y Andrés Jaque desde su Oficina de Innovación Política (2013); lo diagramático como expresión de ideas arquitectónicas (Soriano, 2004); la razón poética incorporada en tectónica contemporánea, visible en la obra de Alberto Campo Baeza (1999); la desmaterialización y levedad, expresadas en los edificios de Jean Nouvel (Nouvel y Baudrillar, 2003) entre otras. Tectónica y estereotomía, operadas mediante la proyectación y el trabajo de los humanos en contacto o mediante robots con los componentes o el material que constituye la obra.

Es así como a partir de este panorama de la arquitectura contemporánea, que esta investigación, haciendo un análisis de las perspectivas de la realidad, relacionada a condiciones dinámicas, las abordará como contexto de obras de arquitectura que, a partir de seis estudios de caso durante los quince primeros años del siglo XXI, presentan características donde es posible evidenciar que la tectónica cede el paso a los ámbitos dinámicos, conjugándose ambos o tomando las dinámicas el control de la generación o experiencia de la arquitectura. Estos casos serán explicados a partir del intercambio de las características tectónicas o estereotómicas con o por técnicas procedentes de otras disciplinas, como: los pulverizadores de agua (indeterminación), la flotación de un globo de helio (inestabilidad), las posibilidades ópticas y físicas de los materiales tanto en una barra de acrílico (blando, peludo y luminoso), como en el acero pulido (contexto como materialidad),el proceso del gusano para generar seda (incertidumbre), la mezcla de una bacteria con arena (proceso de generación cultivada, el albañil o cantero solo engendra no proyecta).

Para lograr el objetivo, se ha organizado este artículo en tres secciones además de la introducción: 1) perspectivas del mundo contemporáneo, donde se explican las cuatro vías seleccionadas para entender la realidad desde las cuales se fundamentarán las dinámicas y sus ámbitos, hacia la segunda parte; 2) los estudios de caso explicados desde la tectónica que cede el paso a los agenciamientos; 3) la conclusión, que a través del discurrir de las nociones de tectónica y estereotomía explica las condiciones de los ámbitos dinámicos.

\section{Perspectivas del mundo contemporáneo}

Determinar como la tectónica del espacio arquitectónico le cede el paso a los procesos espaciales que le imprimen a la arquitectura características dinámicas. Conduce a incursionar en el contexto del pensamiento y las estructuras epistemológicas de la segunda mitad de siglo XX y lo que va del siglo XXI, correspondiente a visiones relacionadas con condiciones dinámicas.

Para esto, se inicia con la revisión de perspectivas que, abordan la crisis del paradigma estructuralista; en esta confluyen puntos de vistas con características complejas y dinámicas que buscan construir una episteme para comprender esta condición. Entre la multiplicidad de enfoques existentes se seleccionan las que guardan relación con la arquitectura y las lógicas que pudieran condicionar la arquitectura contemporánea desde ámbitos dinámicos, entre estos: El Rizoma propuesto por Deleuze y Guattari en el año 1978 (2010), la complejidad postulada por Edgar Morín (1999), la modernidad vista desde la liquidez por Zigmunt Bauman (2004) y el modo fluyente planteado por David Bohm (2008).

ACE, 14 (4.2) CC BY-ND 3.0 ES | UPC Barcelona, España | Ámbitos dinámicos. De cómo la tectónica cede paso a los 
El concepto de rizoma propuesto por el filósofo francés Gilles Deleuze (1925-1995) y el psicoanalista Félix Guattari (1930-1992) aparece dentro del libro Mil Mesetas como un reflejo del rechazo de los autores por las organizaciones jerárquicas en favor de relaciones más rizomáticas donde las circunstancias cobran tanta relevancia como las sustancias. Esta posición se presenta como otro paradigma de interpretación de la complejidad del mundo contemporáneo, explora lógicas que se aproximan a los fenómenos del caos, a los procesos de mutación y las formas de mediación perfilando estadios de heterogeneidad, multiplicidad, conectividad, desplazamiento, ramificación y, por, sobre todo, dinamicidad. En este sentido, el rizoma es una entidad que no cesa en su acción de conectar, por lo que no produce finales, sino que, por el contrario, su proceso inacabable va siendo y haciendo dinámica. "Un rizoma no empieza ni acaba, siempre está en el medio, entre las cosas, inter-ser, intermezzo. El árbol es filiación, pero el rizoma tiene como tejido la conjunción ‘y...y........ En esta conjunción hay fuerza suficiente para sacudir y desenraizar el verbo ser" (Deleuze y Guattari, 2003, pág. 57).

El rizoma no es una aprehensión lógica u objetiva, puede ser roto, quebrado o fracturado, aprovechando su afán para producir segmentaridad, estratificación, territorialización. El rizoma "procede por variación, expansión, conquista, captura, inyección. [...] [Es] siempre desmontable, conectable, alterable, modificable, con múltiples entradas y salidas, con sus líneas de fuga. [...] Lo que está en juego en el rizoma [...] [es] todo tipo de 'devenires'.” (Deleuze y Guattari, 2010, 25-26 pp.). Así, el agenciamiento surge como otro concepto de estos autores que, en la búsqueda de una filosofía capaz de crear conceptos con consistencia y sin perder nada del infinito, describen sistemas conceptuales abiertos y trabajados por las diferencias, las variables y las contingencias.

El agenciamiento, constituye un término ampliamente utilizado en la filosofía contemporánea y, pese a que ha sido apropiado por otros autores este, en mayor o menor medida, nos remite a la visión rizomática de Deleuze y Guattari. Manuel Heredia (2014) en su artículo "Dispositivos y/o agenciamientos" profundiza al respecto y señala que este concepto es la confluencia de dos afirmaciones: Uno referido a lo relacional, que remite al ensamblaje de elementos heterogéneos en una multiplicidad rizomática en la cual la configuración de los elementos depende de los regímenes de su co-funcionamiento. Y dos, un aspecto procesal, referido a la realidad del presente, el futuro y las posibilidades de componer, descomponer, estabilizar y desestructurar los sistemas de relaciones. Podría añadirse un tercero, derivado del primero, su constante condición de encontrarse entre.

Este aumento de dimensiones y multiplicidad de naturalezas (que incrementan, conforme se establecen más conexiones), configura ámbitos relacionales y sin jerarquías que, traducidas en la arquitectura se pueden manifestar de múltiples formas con el desarrollo de una perspectiva que involucre las dinámicas en la experiencia y generación del espacio arquitectónico. Procesos que ya son evidentes en fenómenos urbanos en contextos de informalidad (2019), la visión de pliegues y fractales en el discurso estético contemporáneo y las estrategias proyectuales (Van Berkel y Bos, 2002; Koolhaas y Mau, 1995; Lynn, 2004), la dialéctica digital y los diagramas de buena parte de la arquitectura contemporánea (Montaner, 2014), entre otras manifestaciones.

Esta visión de una realidad compuesta de multiplicidades en continuidad plegada, replegada y desplegada dibuja una visión compleja que también fue abordada por el filósofo y sociólogo Edgar Morin. Quien propone la complejidad como una perspectiva en apertura que se da al comprender la realidad como sistema. Este autor evidencia como la interrelación de las partes genera emergencias, es decir, la articulación de dichas partes le confieren un sentido al todo que va más allá de la suma de sus partes, ya que organiza las conexiones de lo separado para mostrar cualidades que no se percibían estando apartadas (Morin, 2005).

ACE, 14 (4.2) CC BY-ND 3.0 ES | UPC Barcelona, España | Ámbitos dinámicos. De cómo la tectónica cede paso a los 
Para Morin, el mundo es una totalidad indisociable que necesita ser abordada de manera multidisciplinaria y multirreferenciada en que, lejos de estudiar las esencias en su individualidad, estas deben ser vistas en su contexto e insertas en la globalidad a la cual pertenecen; la complejidad, "debe afrontar lo entramado (el juego infinito de inter-retroacciones), la solidaridad de los fenómenos entre sí, la bruma, la incertidumbre, la contradicción... Así es que habría que sustituir el paradigma de la disyunción/reducción/unidimensionalización (sic) por un paradigma de distinción/conjunción que permita distinguir sin desarticular, asociar sin identificar o reducir" (Morin, 2005, pág. 34).

Es una visión de la realidad, en la cual las ciencias clásicas sustituyen las verdades y las certezas por las posibilidades o como lo expresa Prigogine (1998) "El fin de las certidumbres". En la arquitectura, esta realidad, se demuestra en el proceso de exploración de la complejidad formal que queda en evidencia desde la crisis del Movimiento Moderno y que desde 1966, con los trabajos de Robert Venturi (2008), se viene anunciando y que más próximo a nuestro tiempo, es estudiado en trabajos ampliamente difundidos como Sincronizar la geometría de Borja Ferrater (2006), Las formas del siglo XX (Montaner, 2002) y Sistemas arquitectónicos contemporáneos (2008) de Josep María Montaner donde se plasman estrategias proyectuales y modos de hacer arquitectura para abordar el escenario arquitectónico contemporáneo.

En este contexto, el paradigma de la complejidad configura un nuevo orden en que lo informal, múltiple, no-lineal, indeterminado y abierto dan como resultado una forma de pensar, ver y hacer la arquitectura. Una arquitectura que se exprese desde la co-implicación, indeterminada, borrosa y despejada a la vez para producir fenómenos emergentes que desde la perspectiva de Izuzquiza (2003), esbozan un mundo dominado por los flujos, incertidumbre, diferencia, riesgo, velocidad, levedad, etc. En síntesis, un entorno complejo abierto a relaciones colectivas desde la conjugación de diferencias.

Al atreverse a superponer la visión relacional y cambiante de Deleuze y Guattari, con la complejidad de Morin, aparece la modernidad versada desde la liquidez, bajo la perspectiva del sociólogo, filósofo y ensayista polaco Zygmunt Bauman (1925-2017) quien a finales de la década de 1980 presentara su visión de una sociedad posmoderna y distópica, la cual concibe, como la modernidad líquida. Esta concepción de modernidad surge conjugando las características de la sociedad visionada con conceptos propios del medio líquido como fluidez, cambio, adaptación, flexibilidad, temporalidad, individualidad, entre otros.

La modernidad versada desde la liquidez, bajo la perspectiva de Zygmunt Bauman (2004), constituye una condición contextual para el estudio de las arquitecturas cuyas tectónicas ceden el paso a las dinámicas, ya que de las visiones es la que está, desde la metáfora de lo líquido, caracterizadas por condiciones correspondiente a las dinámicas de fluidos.

Así como la realidad pasó de una modernidad sólida, predecible y controlable a una sociedad maleable en continuo cambio de forma, de la misma manera, la arquitectura ha puesto en crisis la significación del objeto tectónico, poniendo en cuestión estructuras, discursos estilísticos o configuraciones determinadas, mediante procesos de transformación. En lo líquido, lo que cuenta es el flujo de tiempo reducido a la instantaneidad. Sus acciones se sortean, disuelven, derraman e infiltran. Rechaza lo durable y celebra lo efímero. La filtración, escurrimiento y elisión desorganizan sus des-bordes. Para Bauman un rasgo particular de la modernidad es la "diferencia que hace toda la diferencia" (Bauman, 2004, pág. 14), como la propiedad que cambia la relación entre espacio y tiempo. Estas condiciones desde la fluidez muestran posibles características de entornos arquitectónicos que ponen en crisis lo establecido por objetos tectónicos.

ACE, 14 (4.2) CC BY-ND 3.0 ES | UPC Barcelona, España | Ámbitos dinámicos. De cómo la tectónica cede paso a los 
Las visiones antes descritas, han estado marcadas por un discurso que deriva de las ciencias sociales, sin embargo, la crisis del paradigma moderno afectó también las ciencias exactas y tal es el caso de la física que inicia su transición desde el siglo XIX con los trabajos de Ludwig Boltzmann que sienta las bases para el posterior desarrollo de la termodinámica del no equilibrio y los sistemas inestables asociados a las ideas del caos, la auto-organización y las estructuras disipativas. Más recientemente, el físico estadounidense David Bohm (1917-1992), parte de la teoría cuántica y comprende la naturaleza de la realidad como un todo coherente, sin ser estático ni completo, en un constante proceso de movimiento y despliegue, sin separación, es decir que todo actúa e interactúa para conformar, es la coherencia que deviene de la relación fluyente.

Su explicación requiere nuevos modos de usar el lenguaje, el reomodo o modo fluyente (Bohm, 2008), en el cual, el papel básico se le atribuye al verbo y cuyas acciones generarían formas fluyentes que, se funden con otras, sin separaciones ni rupturas tajantes, en el que los movimientos fluyen unos dentro de otros y se mezclan sin cortes abruptos (Bohm, 2008). Este modo fluyente puede inferirse en la arquitectura como dinámicas basadas en acciones inacabadas, incesantes y co-implicadas para constituir espacios arquitectónicos que desprendiéndose de preceptos tectónicos pudieran configurarse mediante dinámicas que comprendan un ciclo continuo, cuyos orígenes pudieran estar en la teoría de Oscar Hansen (1961) de la forma abierta, en la propuesta del Fun Palace de Cedric Price y Littlewood (1968), en la inevitabilidad del transcurrir del tiempo como lo propone Stewart Brand en su libro "How Buildings Learn: What Happens After They're Built" (1994), la arquitectura de la indeterminación de Yago Conde (2000), entre otras visiones que, desde la arquitectura consideren características referentes en esta perspectiva.

Esta serie de perspectivas de manera diferenciada dibuja una realidad con un orden informal, múltiple, no-lineal y abierto en los que el rizoma, el agenciamiento, la complejidad, la liquidez y lo fluyente convergen para ser medio y mediación en los propósitos teóricos que permiten a la arquitectura postular y demostrar cómo arquitecturas existentes en su conformación, experiencia y acción revelan procesos generativos y experiencias más relacionados con las dinámicas que con lo tectónico y estereotómico.

\section{Estudios de caso: la tectónica cede el paso a los agenciamientos}

El surgimiento de tendencias emergentes en la arquitectura es una realidad que ha sido estudiada ampliamente y que queda evidenciada en instrumentos tan explícitos como la Brújula Política de la Arquitectura Global planteada por Zaera-Polo (2016), permitiendo evidenciar una amplia heterogeneidad, desde lo que pudiera comprenderse que la arquitectura contemporánea está caracterizada por una amplia gama de diferencia de visiones y proposiciones. A partir de lo cual se infiere que su instrumento cognitivo es abordado desde lo instrumental. Concepto como forma, fondo, tipo, sistema, estructura, acción, entre otros, son contemplados desde diversas perspectivas y emplazamientos, tributando ellos, desde su singularidad a una arquitectura que, en esta contemporaneidad, se gesta y se experimenta en plural.

Desde la diferencia de perspectivas, esta investigación indaga, mediante estudios de caso, en procesos que le imprimen al espacio características dinámicas, buscando una forma de repensar el conocimiento para la producción y experiencia de la arquitectura. Es así como las obras a analizar muestran un diálogo con otras disciplinas para fortalecer y alcanzar un modo que permita “(...) develar las raíces y antecedentes, las teorías, métodos y posiciones implícitos en el objeto. Además, con esta contextualización se contrarresta la tendencia al individualismo y creacionismo en el que se escudan muchos artistas y arquitectos, rechazando interpretaciones y clasificaciones" (Montaner, 2013, pág. 16).

ACE, 14 (42) CC BY-ND 3.0 ES | UPC Barcelona, España | Ámbitos dinámicos. De cómo la tectónica cede paso a los 
Para profundizar en esto, se hace necesario explicar que, la palabra dinámica está asociada generalmente a la idea de energía, de fuerza, y específicamente en la mecánica, a la idea de movimiento en relación con las fuerzas que lo producen.

Etimológicamente, dinámica proviene del griego dynamikós 'poderoso', de dynamis 'fuerza, poder' de dynasthai 'poder (verbo)', del indoeuropeo duna-, de du-, de deu- 'hacer, ejecutar' (Gómez de Silva, 2001, pág. 226). Desde el punto de vista de la arquitectura y para esta investigación en particular, estas "fuerzas de poder" de las dinámicas se inscriben en los actos, acciones, expresiones, situaciones u ocurrencias que confluyen y se incluyen en la generación de la obra arquitectónica, en las distintas formas del contexto y en la experiencia del habitar.

Esta perspectiva contingente bosqueja una arquitectura donde las dinámicas se abren paso ante los modos que devienen de la configuración y preconcepción tectónica. Mediante el uso de las fuerzas, se cuestiona las configuraciones determinadas, objetuales o envolventes tectónicas para incursionar en agentes y agenciamientos que accionan, reaccionan y transaccionan entre sí y con otros a fin de ir procesando modos de habitar. Se visionan así, dinámicas que niegan la aglomeración, la concentración, la compactación y lo único, para favorecer lo múltiple, la dispersión, el derramamiento, la expansión y la desterritorialización, diagramando en consecuencia una acción de procesal donde estos agentes transaccionan.

Desde las dinámicas, partiendo de las perspectivas expuestas sobre la realidad contemporánea, la arquitectura se complejiza, se expande y difumina sus límites, tanto disciplinares como experimentales, asimilando otras potencialidades de los conceptos de proceso, inacabado, interacción, conflicto y competencia. Así, esta mirada de la arquitectura contemporánea se despliega a partir de la acción confluyente de los agentes, hacia la idea de agenciamiento, atrayendo hacia sí lo ecosistémico, condiciones y características de lo activo, cambiante, continuo, animado y de una condición implícitamente inestable (Gausa et al, 2000).

Agentes que excitados dinamizan, reconfiguran, multiplican, entrelazan, intercambian y transaccionan. Agentes como energía dinámica, como potencia activa y propulsora que procuran que la arquitectura ya no esté atada a las condiciones estáticas, estables y perennes sino a una disposición abierta, intermedia y vacilatoria, sin estadios finales, completos o concluidos, en proceso de continua conformación, deformación, transformación y fluctuación en sus geometrías. Es decir, génesis y experiencias espaciales en estado transitorio. Agentes no únicos, dominantes, con modos de ser jerárquicos, sino colectivos, que establecen alianzas, contagios y desterritorializaciones, generando agenciamientos en este devenir de acciones.

Mientras el agenciamiento definido por Deleuze y Guattari es aumento de multiplicidades, que consideran una noción más amplia que la forma y el proceso (Guattari, 2004); los agenciamientos, desde la perspectiva de las dinámicas en la arquitectura, son acciones o actos que conjugados permiten la emergencia de acontecimientos que producen el accionamiento de las fuerzas que contribuyen a la génesis y experiencia dinámicas en la arquitectura. No se trata de partes independiente articuladas de manera estable, sino fenómenos, multiplicidades, imprecisiones, conjunciones, etc., que desde acciones estratégicas se organizan para generar una arquitectura inacabada, coherente, desde el habitante, el medio y en continuidad con él.

Las arquitecturas producidas y productoras a partir de tales agenciamientos, que se han abierto paso ante la tectónica y la estereotomía, se presentan como motores para la generación de entornos, donde predominan las condiciones dinámicas. En este sentido, las dinámicas en la arquitectura constituyen condiciones abiertas, flexibles, receptivas, donde todo se transforma en oportunidad,

ACE, 14 (4.2) CC BY-ND 3.0 ES | UPC Barcelona, España | Ámbitos dinámicos. De cómo la tectónica cede paso a los 
para que los emplazamientos y puntos de vista de la arquitectura fluyan en búsqueda de emergencias a partir de la complejidad de relaciones entre procesos y disciplinas múltiples, conformando ámbitos.

De este modo, los ámbitos, no son vistos como contornos que determinan y delimitan, sino como medios donde se relacionan acciones o disciplinas para configurar una emergencia. Un medio de condiciones abiertas, flexibles y receptivas, donde la crisis se transforma en oportunidad, para que los puntos de vista de la arquitectura fluyan a partir de la complejidad de relaciones entre formas y disciplinas múltiples.

Es entonces que desde está visión construida a partir de las nociones de dinámicas y ámbito aquí definidas, se han explorado arquitecturas que, con una visión contemporánea, abordarán y demostrarán agenciamientos posibles a través de su generación, materialidad y experiencia, mostrando un distanciamiento de los preceptos tectónicos y estereotómicos para aproximarse a una lógica más cercana a los modelos de pensamiento y estructuras que delinean las múltiples formas del pensamiento contemporáneo.

Demostrar el desplazamiento en el protagonismo de la tectónica, por condiciones dinámicas en la arquitectura, ha conducido a construir una muestra a partir de una revisión documental y audiovisual de registros sobre la arquitectura contemporánea a partir de la segunda mitad del siglo XX. Se indagó en la producción de publicaciones de editoriales como la Taschen, Phaidon, Actar, Gustavo Gili, El Croquis, Edicions UPC, Metalocus, 010 Publishers, Reverte, Arquitectura Viva, Routledge, Monacelli, Domus. En los repositorios de Universidades como UPC (Universidad Politécnica de Cataluña), UPM (Universidad Politécnica de Madrid), UPV (Universidad Politécnica de Valencia). Vía WEB se buscó en los boletines de arquitectura Archdaily, Plataforma Arquitectura, Afasia y Designboom. De estas revisiones se extrajeron catorce obras y propuestas de arquitectura, mediante la evidencia en su generación o experiencia de condiciones que mostrarán características que estuviesen fuera de los dominios de la tectónica. Estos son: indeterminación, inestabilidad, imprecisión, incertidumbre, deformación, ambivalencia, procesal y/o emergente, desde las visiones referidas por las cuatro perspectivas abordadas sobre la realidad contemporánea. Se analizó cada obra desde estos criterios, quedando cinco pabellones y una propuesta como estudios de caso definitivos. La propuesta que, si bien sale de la muestra como excepción en su tipología, refuerza la condición dinámica de la arquitectura que busca explicar esta investigación.

De esta forma se enuncian: La incertidumbre e imprecisión inmersiva hecha de vapor de agua por los arquitectos de Diller y Scofidio. El despegue inestable de la cubierta del Pabellón para la Serpentine Gallery en 2006 desarrollado por Koolhaas y Baldmon. El reflejo como acto de desaparición de los componentes tectónicos y duplicación del contexto sobre un suelo que se discurre en los jardines de la Serpentine Gallery, durante el verano de 2009 propuesto por Sanaa. Las 60.686 barras de acrílico, trabajando como medio óptico, conforman un organismo luminiscente, "blando y peludo" (Dalí, 2004), expuesto como pabellón en la Exposición Universal de Shangai en 2010, elaborado por el estudio de Thomas Heatherwick. Gusanos de seda como tejedores del cerramiento de una cúpula en el MIT Lab desarrollado por Neri Oxman y su equipo. Y, por último, un proceso emergente, producto de la convivencia de dos organismos provenientes de diferentes ecosistemas, producido a partir de un ensayo de laboratorio que forma parte de la Tesis de grado de Magnus Larsson.

\subsection{Incertidumbre inmersiva. Blur Building. Diller \& Scofidi. 2000}

El Blur Building de Diller \& Scofidio, construido en el año 2000 (Figura 1), marca el inicio de esta muestra al ser uno de los primeros edificios del siglo en desafiar las lógicas de la arquitectura, construido más allá de la forma, peso, materia, escala, significados, tipo o rasgos distintivos; es un pabellón que se evapora y deforma como el vapor de agua. Más que ser una alegoría a una nube 
suspendida sobre el Lago Neuchâtel, sus autores lo asocian con la idea de ser un edificio difuso, una arquitectura cuya expresión radica en el sentido inherente a la concepción de lo difuso, esto es, de la imprecisión e indeterminación de lo que es una nube. "Una forma nube es aquella que se produce por el equilibrio de lo que sucede en su interior y lo que le está rodeando: no es constante, demasiado voluble, translucida, con perfiles vagos y borrosos. Sus muros se definirían por estadísticas de densidad" (Soriano, 2004, pág. 51).

Figura 1. Blur Building 2000, Diller \& Scofidio

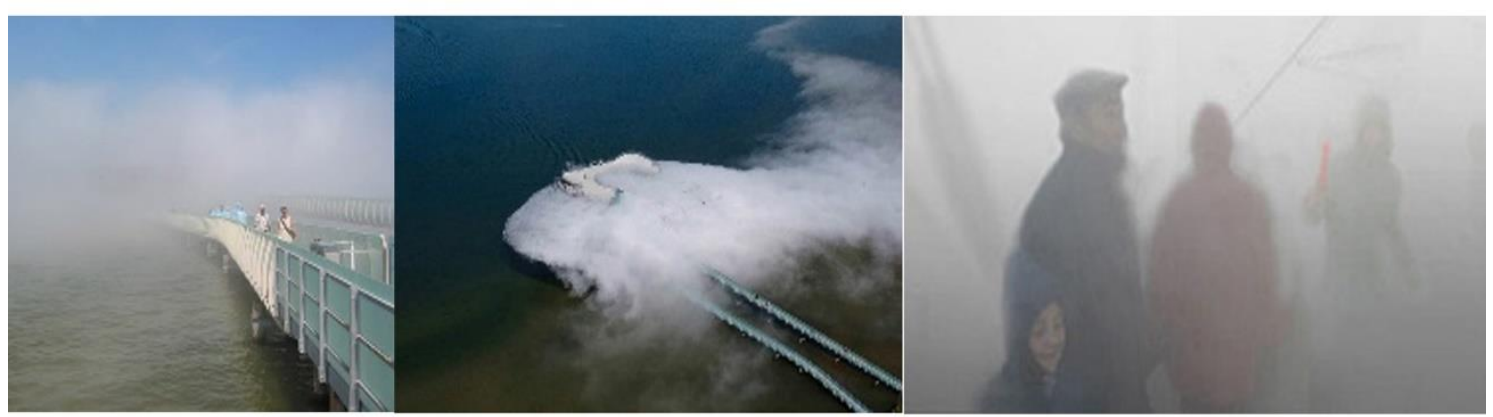

Fuente: http://en.urbarama.com/project/blur-building @ Beat Widmer [tbc]

Basada en el diseño estructural, denominado tensegridad de Buckminster Fuller de 1950, el Blur Building se construye a partir de una estructura ligera que queda envuelta por una neblina generada a través del agua bombeada desde el lago y que es filtrada y nebulizada por 31.500 pulverizadores de alta presión dispuestos a cada 1,20 metros. El resultado fue un pabellón capaz de acoger, en una masa gaseosa suspendida sobre el agua, 400 personas cuyas referencias acústicas y visuales, quedan cegadas al estilo de José Saramago en su Ensayo sobre la Ceguera (2001) por el blanco del vapor de agua y el ruido monótono de los pulverizadores.

Más allá de la temporalidad del pabellón, lo efímero se traduce en plantas y fachadas que están en un constante cambio, los límites y posibilidades de la arquitectura quedan expuestos a la incertidumbre, inestabilidad y la ausencia de la tectónica y estereotomía de los muros. Si bien la condición de su soporte estructural se erige desde la tectónica, sus cerramientos y experiencia espacial se encuentran en el campo de las dinámicas.

Es el agenciamiento entre el agua nebulizada, la humedad, la dirección y velocidad del viento, el encargado de construir una forma sin forma (Soriano, F., 2004) como fuerzas dinámicas cambiando constantemente su configuración, debido a las alteraciones de estas variables meteorológicas, convirtiendo al espacio y su arquitectura en un lugar para la confusión y desenfoque, anulando la visualidad, poniendo en duda los preceptos arquitectónicos occidentales, tales como, escala, proporción, solidez, percepción visual, etc. Constituye un espacio visualmente denso, difuso, y por ende "desenfocado"; sensorialmente húmedo y frío; formalmente inestable e indeterminado; cargado de experiencia ambiental; es un espacio sin proporción, sin referencias, "sin profundidad, sin escala, sin espacio, sin masa, sin superficie" (Galofaro, 2004, pág. 155).

Elogio a la indeterminación que rompe con el esquema de pura visualidad de la arquitectura occidental para sumergir el visitante en una experiencia sensorial, afianzándose en lo táctil, es decir de contacto y penetración constante en la materialidad de la forma arquitectónica. Es así como la vaporización del agua ha generado aquí una condición arquitectónica que creó una forma sin resistencia superficial que colmó un espacio donde materia y vacío estuvieron en constante contacto con el cuerpo del visitante. 
Elizabeth Diller y Ricardo Scofidio en sus propuestas revelan una perspectiva que surge de una investigación teórica, que trabaja en, con, desde y a través del arte para una obra que, consecuentemente esta liberada de los rigores, buscando aspirar a develar, revelar, descubrir y reinventar posibilidades y experiencias.

\subsection{Despegue inestable de la cubierta. Pabellón para la Serpentine Gallery. Rem Koolhaas y Cecil Baldmond. 2006}

El pabellón del 2006 para la Serpentine Gallery de Rem Koolhaas y Cecil Baldmond (Figura 2). Se concibe como un antipabellón desde una dialéctica ante sus homónimos anteriores, hacer del pabellón una rebelión, como si se tratase de un acto de desaparición.

Koolhaas, (Barba, 2018) afirma que él mismo, lejos de centrarse en la estructura, busca fijar la atención en las posibilidades y las actividades que pueden desarrollarse dentro de este. Para esto generó un espacio abierto y diáfano en búsqueda de facilitar la discusión, y que más allá de ser un elemento de arquitectura destacable por su estructura o materiales, se enfocara en redefinir las dinámicas de la Serpentine Gallery como evento. Esto es, abriendo el espacio a las posibilidades de ser, el mismo, una cafetería y auditorio que albergaran transmisiones televisivas, proyección de filmes, maratones de entrevistas, entre otras.

El pabellón se erige a partir de una plataforma horizontal elevada un metro del nivel del suelo, que con 10 metros de ancho, establece una relación directa con la anchura norte de la Serpentine Gallery. Dicha plataforma construida a partir de una estructura de acero, propiciaba el soporte de una superficie realizada con placas metálicas perforadas. Sobre ella en su interior se albergó el programa de actividades que, más allá de ser limitadas por su configuración, este se presenta como un espacio de código abierto que puede ser configurado conforme a las necesidades y dinámicas que se albergaron. Esto fue posible gracias a prismas modulares móviles multipropósito. El recinto interior queda definido a partir de una plataforma circular central, delimitada por una serie de paneles de policarbonato translucido de 5 metros de altura, formando una pared doble de 1,6 metros de espesor, habilitando así, un espacio intermedio, tras el cual se desarrollaba el espacio principal, que por su condición, permitían un dialogo constante y velado entre el interior y el exterior (Barba, 2018).

La cubierta fue materializada mediante un volumen inflable de forma ovoidal, elaborado a partir de PVC semitransparente, inflado con helio y aire que se deformaba (ajustando su volumen y forma), subía y bajaba de acuerdo a las actividades que se realizaban. Función que facilitaba el control climático del interior del espacio. Pudiendo oscilar su altura entre 20 y 24 metros (Barba, 2018). Estos movimientos los realizaba gracias a que estaba despegada de los cerramientos traslucidos del recinto. La deformación del volumen por el acondicionamiento climático debido al uso, el desprendimiento de la cubierta del resto del pabellón, la inestabilidad debida a su contenido de helio y aire, y la fuerza que este aplicaba para poder elevarse y soltarse son las condiciones que caracterizan a este pabellón como una arquitectura cuya tectónica de la cubierta ha cedido el paso a los agenciamientos para que las dinámicas predominen en este componente que se superpone sobre el espacio.

Aquí la cubierta no transmite las cargas al suelo, sino que su inestabilidad y deformación volumétrica son debidas a los agentes meteorológicos. Lo que para la tectónica constituye un trabajo articulado para vencer la gravedad (Campo Baeza, 1999), en este caso, se vuelve un dominio atmosférico, ya que debía estar atada para evitar que el vuelo se apropiase de ella. De esta manera, se crea el agenciamiento en una arquitectura dispuesta sobre la tierra, que solo la toca sutilmente, no se "funda" en ella. Un pabellón en el cual, uno de sus componentes escapa del ordenamiento tectónico para otorgarle su responsabilidad a las dinámicas atmosféricas. 
En este sentido el proyecto abre importantes cuestiones sobre el devenir de la arquitectura contemporánea y que, hasta el momento, siguen en discusión. Butragueño (2015) afirma que Rem Koolhaas en su curaduría para la Bienal de Venecia, marcó un balance de su etapa performativa que viene mostrando desde el 2007 a la fecha, cuando en su visión de los Elementos de Arquitectura, intenta volver a los orígenes de esta al considerar que los recursos actuales se encuentran agotados y buscando establecer una reconstrucción de los mismos para abrir nuevos contextos y conceptualizaciones en el campo de la arquitectura.

Figura 2. Serpentine Gallery Pavillion 2006. Rem Koolhaas y Cecil Balmond

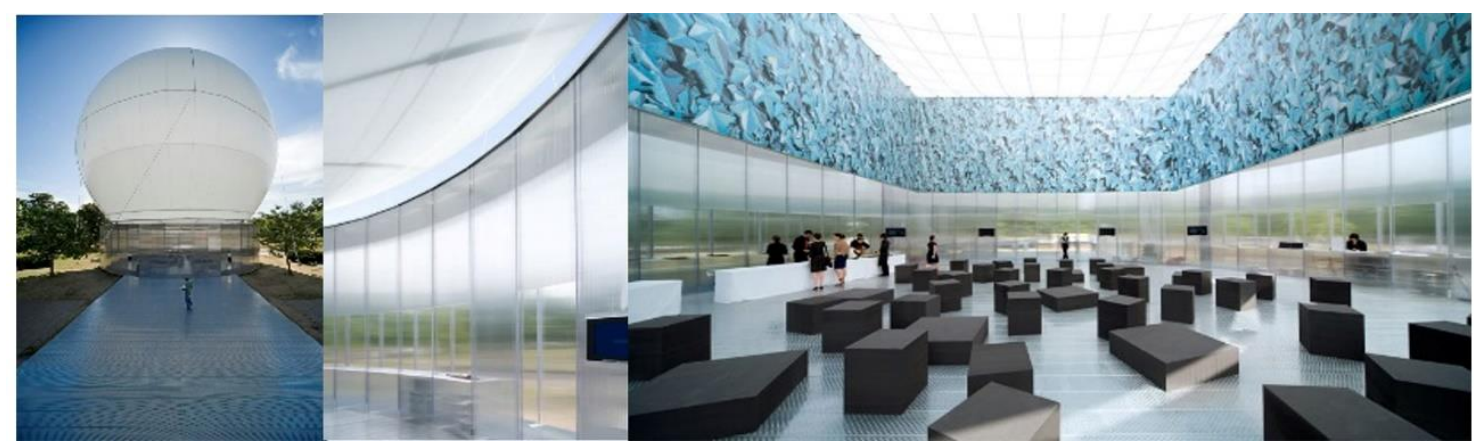

Fuente: http://www.flickr.com/photos/sylvaindeleu/1351494468/

http://img139.imageshack.us/my.php?image=remserp015a2lm.jpg

\subsection{Desaparición de los componentes tectónicos. Pabellón para la Serpentine Gallery. SANAA. 200}

El Pabellón para la Serpentine Gallery de SANAA, 2009 (Figura 3), está conformado por una cubierta delgada de aluminio reflectivo, en ambas caras, de $26 \mathrm{~mm}$ de espesor, que descansa sobre 115 soportes cilíndricos de aluminio, con un diámetro de entre los 40 y $60 \mathrm{~mm}$, distribuidos al azar, configurando un espacio derramado entre la vegetación del jardín. A pesar de la precisión y pulcritud del trabajo de Sejima y Nishizawa, como el propósito del pabellón es derramarse en el paisaje de los árboles y caminos del jardín más allá de cualquier norma o precepto, las alturas varían, al igual que la ubicación de las columnas (que llegan a estar incluso en el césped).

La cubierta configura el reflejo en sus dos caras opuestas, ubicado entre la unidad suelo y cielo, para crear él mismo una separación, y manifestar un espesor visible de reflejos, pero inexistente en su dimensión. Un pabellón que, buscando desaparecer en su materialidad reaparece como medio de réplica del contexto, con lo cual entran en juego los apoyos. Reflejos en los cuales, por un lado, el espacio habitado pasa a tener como techo el contexto que queda en su inferior y es ese espacio, contenido en esa reflexión de la membrana, el que le otorga un espesor virtual. Por otro lado, la reflexión de la cara superior hace que el espesor se haga infinito, conteniendo la dimensión de su contexto reflejado, el cielo. Y por un tercer lado, la materialidad reflectiva y dimensión de los apoyos hacen que su encuentro con la cubierta y su presencia en el espacio sean casi inexistentes. Suelo, cielo, entorno como contextos reflejados sobre un suelo derramado entre los árboles del jardín buscando transformar a los componentes tectónicos en un acto de desaparición de su constitución para otorgarle una doble presencia al contexto, al soporte y al medio circundante.

Es así como uno de los aspectos que cobra relevancia, es la simpleza los detalles, el encuentro de los elementos tectónicos. Lo que muestra que esta propuesta de SANAA busca llevar la arquitectura más allá de la tectónica, aspirando hacerla desaparecer, llevándola a la mínima expresión, buscando

ACE, 14 (4.2) CC BY-ND 3.0 ES | UPC Barcelona, España | Ámbitos dinámicos. De cómo la tectónica cede paso a los agenciamientos. DOI: http://dx.doi.org/10.5821/ace.14.42.8288 
su ausencia material mediante el reflejo del contexto y empezando a utilizar el vacío y el paisaje como elementos de construcción.

Carabias (2016) analiza las conexiones entre los postulados de Mies Van der Rohe y el trabajo de Sejima y Nishisawa, releyendo este e interpretando el rol de los discursos arquitectónicos para cada uno, puede entreverse, que al igual que el pabellón de Barcelona de Mies, buscó utilizar el reflejo de los materiales para acercar al pabellón a la inmaterialidad. Sin embargo, a diferencia de Mies, cuya reflexión se encuentra en los muros exaltando también su materialidad, en este pabellón, la reflexión se encuentra en la horizontal, mediante una superficie especular que, al replicar fielmente el reflejo, desaparece ante la mirada, la materialidad como primer plano visible. Es así como puede verse en este pabellón la búsqueda de eliminar el rastro de los componentes tectónicos de la arquitectura en su especialidad, que se precisa más allá del adentro y el afuera, del interior y exterior, de lo natural y lo construido, del límite y el recorrido, del centro y la periferia.

Un organismo reflectivo que busca desaparecer reflejando sus contextos, infiltrándose entre ellos como otra dimensión y a su vez entremetiéndose en los intersticios del parque, derramándose en diferentes direcciones y haciendo posible la existencia de un horizonte tangible que separa el cielo del suelo. Agencia la arquitectura mediante la separación del reflejo, la perdida de definición de la realidad y la búsqueda de la anulación de los límites de la arquitectura (Machado, 2013). Es la reversibilidad de la experiencia, la vigilancia del reflejo que define el interior de la arquitectura más que cubrir busca ser testigo instantáneo de las acciones, como si de un acto reflejo se tratase.

Figura 3. Pabellón para la Serpentine Gallery de SANAA, 2009

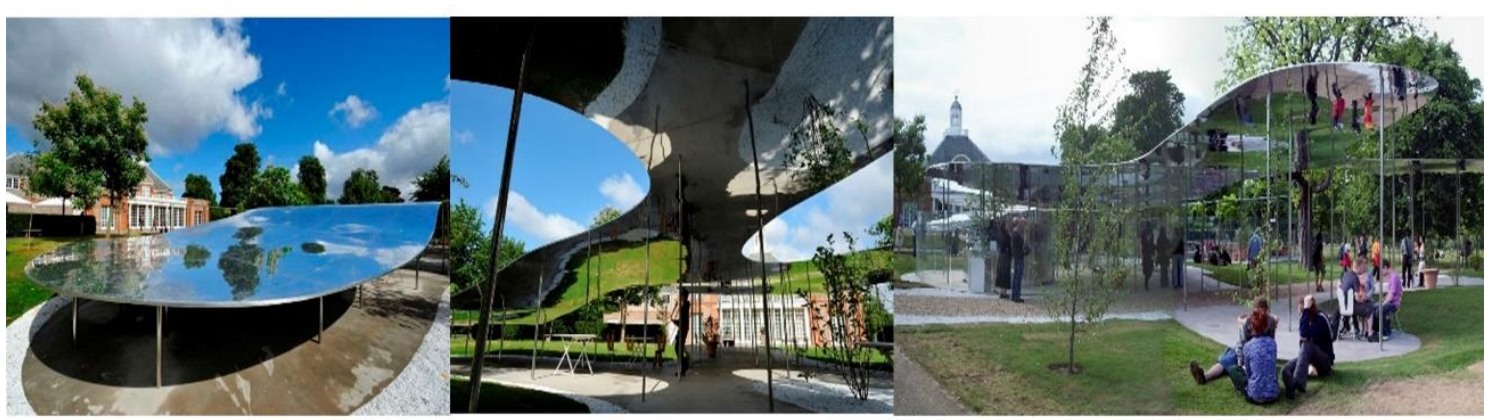

Fuente: http://www.e-architect.co.uk/london/serpentine_gallery_pavilion_2009.htm

http://www.plataformaarquitectura.cl/2009/07/12/abre-serpentine-gallery-2009-kazuyo-sejima-ryue-nishizawade-sanaal

\subsection{Luminiscente, "blando y peludo". Pabellón del Reino Unido. Expo de Shangai. 2010}

El Pabellón del Reino Unido para la Expo de Shangai 2010 del Estudio de Heatherwick (Figura 4), también llamado la catedral de las semillas, surge como reflexión de los proyectistas a la temática de una vida urbana sostenible. Bajo la premisa de explorar las relaciones entre la naturaleza y ciudad se dispuso de un prisma de $100 \mathrm{~m}^{2}$ de espacio interior constituido por 60.686 varillas de acrílico y fibra óptica transparente con una base cuadrada de $20 \mathrm{~mm}$ y un largo de 7,5 metros en cuyos extremos fueron ubicadas una o varias semillas. Durante el día, estas varas aprovechan la luz del día para iluminar el interior y, por la noche, emisores de luz en cada barra permiten que la estructura se ilumine. Por la configuración del mismo, se percibe hacia el exterior como un dispositivo cinético, que interactúa y se mueve con el viento, casi como organismo "blando y peludo" (Dalí, 2004).

ACE, 14 (4.2) CC BY-ND 3.0 ES | UPC Barcelona, España | Ámbitos dinámicos. De cómo la tectónica cede paso a los agenciamientos. DOI: http://dx.doi.org/10.5821/ace.14.42.8288 
Ha recibido su connotación de catedral por su interior, el cual se percibe como un templo en penumbra sutilmente iluminado por las puntas de los filamentos de fibra óptica que, en conjunto, conforman un entorno estrellado, que además por la sensibilidad a la luz externa, genera una luminosidad dinámica y cambiante. Es así que las características ópticas, agenciadas mediante la aliteración de transparencias lumínicas, conforman en el interior una constelación de luz sensible a los cambios de iluminación y dirección y velocidad del aire del entorno. En su exterior, mediante el movimiento de los filamentos, se percibe como un organismo leve, blando y peludo. La iteración de estos filamentos, que construyen un prisma (lumínico y de forma), se conjugan para conformar un proceso complejo de resonancia lumínica que, hacen del interior un espacio donde no existe diferencia entre lo que se expone y lo que lo contiene. Se crea un entorno donde lo que se expone y lo que lo contiene se hace uno, esto es, lo que envuelve el espacio es fuente de luz y cofre donde se encuentra lo expuesto. De esta manera se conjuga iteración, ambivalencia, y óptica para construir un entorno de dinámicas complejas, cuyo exterior cede a la presión del viento.

Figura 4. La catedral de las semillas. Estudio de Heatherwick. 2010

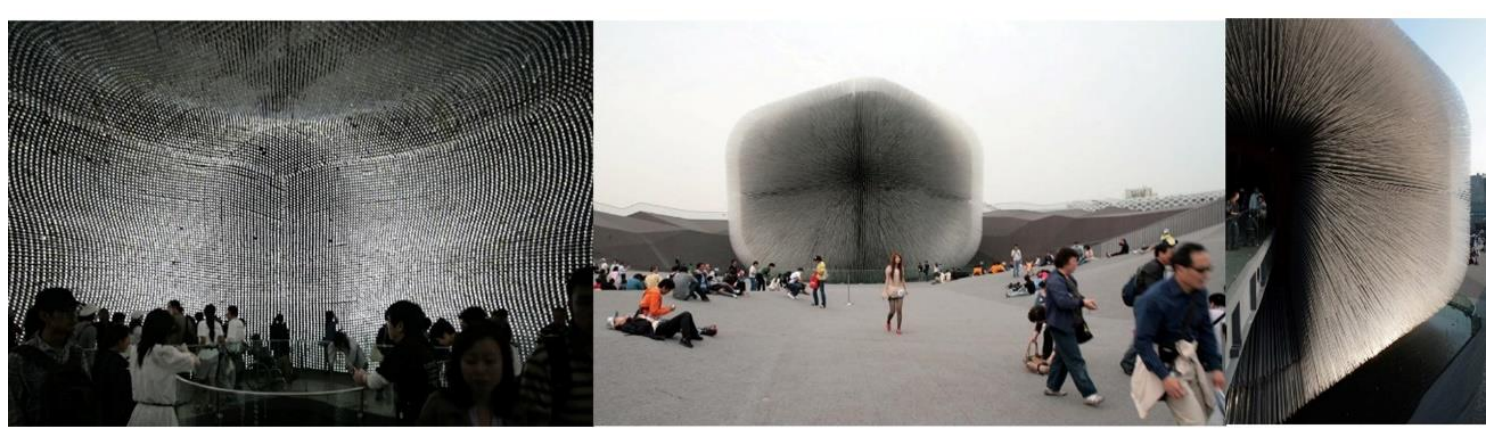

Fuente: http://www.detail-online.com/architecture/topics/designing-the-seed-cathedral-007420.html

\subsection{Gusanos de seda como tejedores del cerramiento. Pabellón de Seda. MIT Media Lab's Mediated Matter Group. 2014}

El "Pabellón de seda" es desarrollado por el MIT Media Lab’s Mediated Matter Group (Figura 5), grupo que integra la investigación científica, el diseño digital y la construcción biomimética. Fue elaborado bajo la dirección de Neri Oxman en colaboración con el Wyss Institute de la Universidad de Harvard y la Tutfs University.

El pabellón surge a partir de la estructura de un domo geodésico de 3,65 metros de diámetro compuesto por 26 paneles poligonales. Explora la relación entre la construcción biológica y las tecnologías de fabricación digital. Dichos paneles, fueron tejidos con hilo de seda por un brazo robótico CNC (Control Numérico por Computadora) que, basado en la capacidad del gusano de generar un capullo a partir de un hilo, sigue el algoritmo geométrico del gusano para tejer cada módulo en distintos niveles de densidad. Posteriormente con la concreción de la estructura, un enjambre compuesto por aproximadamente 6.500 gusanos de seda (bombyx mori), o las impresoras biológicas como también se les conoció durante la experiencia, se encargó de rellenar los espacios vacíos por lo que, las variaciones entre la transparencia y densidad geométrica dentro del pabellón varían conforme los patrones descritos por los insectos. Esto es, los espacios vacíos del cerramiento del domo estuvieron a cargo de las acciones de estos insectos, su construcción, en un medio previamente dispuesto, es un proceso que se desarrolla ajeno al pensamiento, preconcepción y hacer humano. Por muy diminuto que sea su espacio de actuación, hay aquí un vestigio de un proceso emergente, no proyectado. 
El pabellón es una muestra de las posibilidades que se abren con la transformación de los medios de producción y señala uno de los muchos enfoques por explorar en el manejo de tecnologías y medios de fabricación, abriendo líneas de acción hacia estrategias que generen sinergia entre lo natural y lo artificial, lo construido y lo emergente, el hombre y el ambiente.

Como una crisálida traslucida variable, este pabellón combina fabricación digital con el proceso biológico del tejido de seda de los gusanos, demostrando una mediación entre fabricación humana de alta tecnología con procesos naturales de subsistencia. Sinergia entre lo digital y lo natural que produce dos escalas de tejido, la primera (digital) que sirve de soporte a la segunda (natural), que por su diminuto tamaño es imposible lograr a través de medios artificiales. Seres vivos tejiendo materia para su transformación, extendido en un pabellón que transforma la articulación tectónica de medios artificiales en una transacción entre lo natural y lo artificial. (Oxman et al, 2014). Tejido que es elaborado por insecto, el arte de la técnica aquí radica en el medio que propicia el ser humano para que estos animales intervengan.

Figura 5. Pabellón de seda. MIT Media Lab’s Mediated Matter Group. 2014

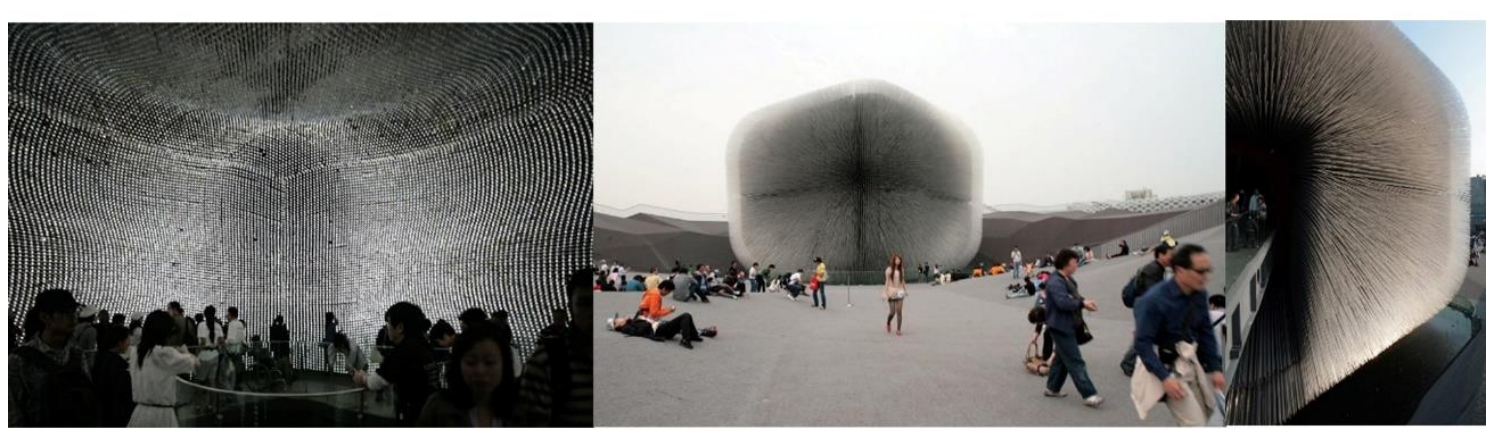

Fuente: http://www.archdaily.com/384271/silk-pavilion-mit-media-lab/

\subsection{Proceso emergente. Duna como arquitectura. Magnus Larsson. 2009}

Desde sus inicios, la arquitectura y la construcción han estado condicionadas por las limitaciones físicas y tecnológicas de los materiales. Esta época, al igual que sucedió a finales del siglo XIX, se encuentra ante una revolución en la fabricación y pertenencia de ciertos componentes a determinados ámbitos. Magnus Larsson, desde sus investigaciones, contribuye a comprender como estos ya no son rígidos, sino dinámicos y emergentes.

Los recientes avances en química, bioquímica, física y computación permiten comenzar a dibujar nuevos caminos y posibilidades para lograr casi infinitas alternativas ante problemas que hoy aquejan nuestra realidad. Uno de estos problemas fue adoptado por Larsson quien, como estudiante de la Architectural Association en Londres, propuso una solución ante el proceso de desertificación del norte de África con una muralla de 6.000 kilómetros de longitud a lo largo del Desierto del Sahara (Figura 6), la cual ofrecería una combinación de viviendas para refugiados en muro de contención para detener la expansión del desierto construido a partir de arena y una bacteria.

Una propuesta de estas dimensiones bajo materiales y procesos de construcción convencionales resultaría una empresa casi imposible. Sin embargo, Larsson, desde sus estudios en el Laboratorio de Interacciones del Suelo propone utilizar Bacilus Pasteuri, un microorganismo común y de fácil acceso en pantanos y humedales que, bajo condiciones específicas es capaz de solidificar la arena suelta y convertirla en arenisca y así "Transformar la duna en arquitectura" (Larsson, 2009).

ACE, 14 (42) CC BY-ND 3.0 ES | UPC Barcelona, España | Ámbitos dinámicos. De cómo la tectónica cede paso a los 
Una arquitectura que según Manaugh (2009) semeja lo que Michael Welland en su libro Sand, describe como la lógica de las dunas; una estructura que se comporta como los arcos de las catedrales góticas en la transmisión de la carga del techo hacia el suelo, pero con la particularidad, de que estas se mueven y desplazan.

Esta dinámica de transformación y anti-desertificación no es reciente, existen métodos tradicionales y vernáculos que implican la plantación de especies vegetales, vallas y muros para atrapar y controlar la arena, sin embargo, las dunas solidificadas de Larsson no sólo detienen el avance del desierto, genera una barrera habitable que permite habitar la duna, generar agua y sombra y una reducción considerable de la temperatura a favor del confort térmico. Se establece con esta propuesta una dinámica de transformación natural, desde lo natural, es decir, un organismo vivo actuando sobre un material inerte, un proceso emergente provocado por la asociación de dos organismos de ambientes disímiles.

La arena por si sola es un elemento simple, minúsculo, pero que en conjunto y bajo agentes se transforma en complejo, activo, en constante cambio a pesar de ser el mismo, y que, en conjunción con un organismo vivo procedente de otro ecosistema, ofrece la posibilidad de convertirse en estereotomía natural que ocupa el intersticio entre lo natural y lo artificial, una caverna, refugio y paisaje.

Figura 6. Duna como arquitectura. Magnus Larsson. 2009

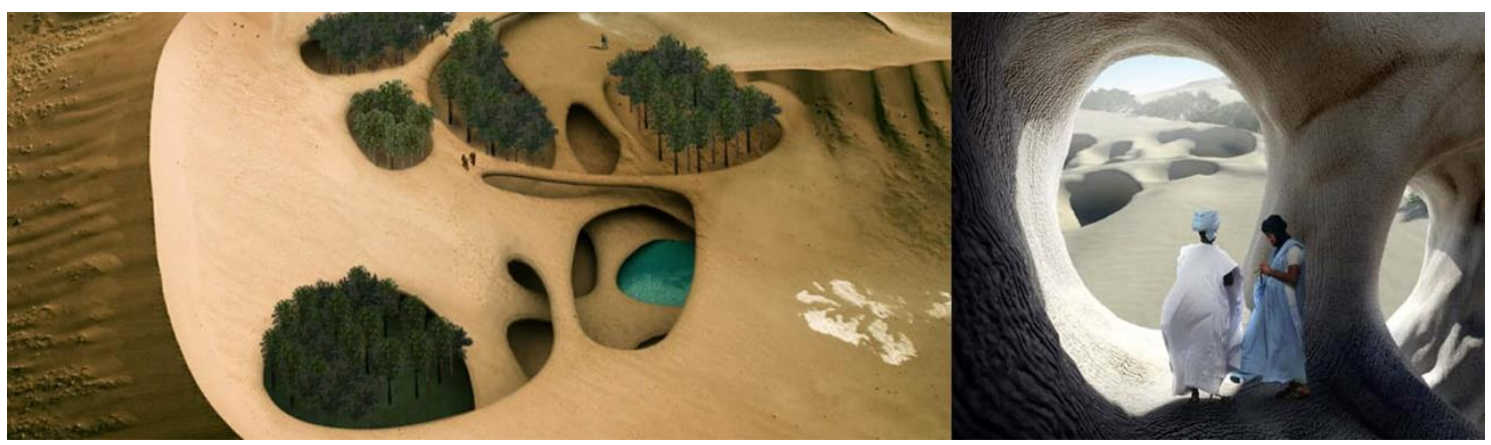

Fuente: https://islamicartsmagazine.com/magazine/view/sahara surreal - magnus larsson/ https://www.designboom.com/architecture/magnus-larsson-sculpts-the-saharan-desert-with-bacteria/ (c) Magnus Larsson

\section{Conclusiones. Ámbitos dinámicos desde un discurrir tectónico}

La comprensión de las nociones sobre tectónica y estereotomía, concebidas como un arte técnico, ético y poético, evidencian que estos conceptos devienen de un proceso que es controlado, desde sus orígenes y en todas sus etapas, por el proceder del ser humano. Cada componente, cada acción, cada gestión, cada definición son programados, proyectados y preestablecidos desde la mano y el pensamiento del hombre.

La técnica en la que se inscriben la estereotomía y la tectónica producen características que le confieren a la arquitectura estabilidad, resistencia, estática e integridad. Técnicas que son conjugadas en objetos, envolventes, cuerpo, organismos tangibles definidos y determinados. Arquitecturas que se comportan como sólidos escenarios de las formas del habitar. Habitar que puede desarrollarse desde múltiples perspectivas, abarcando desde las más complejas a las más simples. Técnicas que, pueden dar cabida a fenómenos dinámicos, pero cuyos componentes tectónicos y estereotómicos

ACE, 14 (4.2) CC BY-ND 3.0 ES | UPC Barcelona, España | Ámbitos dinámicos. De cómo la tectónica cede paso a los 
no pierden ni ocultan su condición, ya que se encargan de configurar el contexto para que estas se desarrollen.

La contemplación de cuatro perspectivas de la realidad contemporánea, para el cumplimiento del objetivo de la investigación, ha permitido conocer, desde esas visiones, las condiciones del contexto dentro del cual se gesta y se experimenta la arquitectura. Desde la noción de Rizoma (Deleuze y Guattari, 2003), puede inferirse a la arquitectura como medio, esto es, no solo como punto medio, sino también como mediación, como el estar entre, como ámbito, es decir como un "medio que media en el medio para un medio" (Machado, 2018, pág. 115). A partir del abordaje interdisciplinar y multi-referencial de la perspectiva compleja (Morin, 2005), la arquitectura puede permitir permearse desde diferentes modos, estrategias, procesos, disciplinas, etc., que en su interrelación permiten la generación de emergencias. La visión metafórica de la modernidad a partir de lo líquido (Bauman, 2004), sumerge a la realidad en una condición dinámica, desde la cual la arquitectura tanto en su constitución, como en su generación, pudieran adquirir condiciones de fluidez, infiltración, derrame, instantaneidad, propias de los fluidos para incorporarlas a sus componentes tectónicos o sustituirlos. La percepción de la realidad como un modo fluyente (Bohm, 2008) posibilita a la arquitectura comprenderla como un todo coherente, co-implicado, inacabado, incompleto, en constante desarrollo, formación, información y deformación.

Teniendo en cuenta las condiciones arrojadas y extrapolables a la arquitectura y la comprensión de lo que implican los conceptos de tectónica y estereotomía, se desarrollaron los estudios de casos. A través de cada estudio se evidencian como características constitutivas en componentes se han alterado para transformar su condición y hacer que estos se encuentren más relacionados con condiciones propias de los ámbitos dinámicos.

En el caso del Blur Building, los nebulizadores, ubicados en las barras o tensores estructurales, son los que, al borrarlos de la percepción, mediante el vapor de agua, le infirieron a este pabellón el carácter indeterminado, impreciso y deformable. He aquí un componente tectónico que sirve de soporte para dejar que la condición dinámica se accione y domine el espacio.

En el Pabellón de 2006 de la Serpentine Gallery, es la cubierta la que adquiere características que la incorporan a las dinámicas. Es oportuno recordar, que la cubierta es uno de los cuatro elementos de la arquitectura postulados por Semper (2014) y cuyo armazón es también considerado en libro el Estilo (Semper, 1860 en Azpiazu, J., 2013) como parte de la tectónica. La cubierta en este pabellón como volumen elástico, blando e inflable, lleno de aire y helio define su comportamiento dentro de los ámbitos dinámicos, ya que agencia su inestabilidad, deformación, ambivalencia a fuerzas que no se encuentran en el plano de las tectónicas.

En el pabellón para la Serpentine Gallery de 2009, la delgadez en el espesor de la cubierta, la diminuta dimensión en el diámetro de los apoyos, la materialidad en cubierta y apoyos como superficies nítidamente especulares transforman la totalidad de los componentes tectónicos, en agentes dinámicos. Agentes que, como se ha explicado anteriormente hacen desaparecerlos para duplicar el contexto, de lo cual se puede inferir un doble mensaje, la desaparición de la arquitectura como tectónica y la importancia que pudiera estar tomando, en la arquitectura contemporánea la noción de contexto.

En el pabellón que representó el Reino Unido en la Expo de Shangai 2010, las condiciones dinámicas se apropian de la envolvente, que si bien no se hace indeterminada, se muestra como medio ambivalente y cuyo conjunto de elementos, que conforman la envolvente, se perciben endebles. La ambivalencia se evidencia de dos formas, primero como cerramiento y ente para resguarda lo que expone y segundo como medio óptico que actúa de dos maneras, como fuente y receptor lumínico.

ACE, 14. (4.2) CC BY-ND 3.0 ES | UPC Barcelona, España | Ámbitos dinámicos. De cómo la tectónica cede paso a los 
Lo endeble viene dado por la longitud libre hacia el exterior de cada uno de los filamentos de acrílico que la componen, ya que vibran, ondean y chocan entre ellos emitiendo sonidos, como si se tratase de un organismo, repitiendo nuevamente la frase de Dalí (2004) "blando y peludo".

Otro orden de condiciones se presenta en los casos faltantes y tienen que ver con su proceso de generación, ya que su apariencia es como las de las arquitecturas producto de las artes tectónicas y estereotómicas. Uno es un domo y el otro un conjunto de cavernas. La dinámica está en su emergencia

El pabellón de seda muestra un proceso de hibridación, un medio tectónico que se comporta como soporte del proceso del tejido del gusano de seda. Se crea una envolvente tectónica construida a partir de procesos manuales, mecánicos, robóticos y digitales para que un insecto sea el que, desde su comportamiento natural, defina el modo como se teje el cerramiento. Si es el gusano el que teje el cerramiento, el tejido no es aquí un arte ya que, al perder su producción desde lo humano, no puede haber arte. Es entonces que, no puede considerarse ni arte textil, ni tectónica (Semper, 1860 En Azpiazu, J., 2013). Lo que hace el gusano de seda es un proceso que genera una emergencia, que deviene de una condición dinámica propia de un ser vivo en sus procesos de subsistencia.

La Duna como arquitectura, se sirve del proceso metabólico que tiene la bacteria en sinergia con la arena. Un proceso metabólico ensayado en laboratorio, que generará unas condiciones habitables de acuerdo a como vayan desarrollando estos procesos metabólicos. Lo que se quiere decir es, que la obra arquitectónica, no es proyectada, no es preconcebida, no es construida a partir de las manos humanas o mecánicas y robóticas programadas por el hombre. La producción de la arquitectura se debe aquí a un proceso emergente que pudiera denominarse como proceso de generación cultivada. En este caso, similar al anterior, pero de manera extendida, la estereotomía no puede considerarse arte y tampoco una de las artes técnicas (Semper, 1860 en Azpiazu, J., 2013), ya que, si su origen es humano, su construcción, producción, organización, etc., deviene de procesos biológicos entre el mineral y el organismo.

Los estudios de caso, aquí desarrollados, prefiguran un posible cuerpo de estudios de la arquitectura que comprende a esta realidad contemporánea sumida en condiciones complejas, dinámicas, inacabadas e intermedias.

La comprensión de la arquitectura desde el ámbito dinámico en una realidad, visionada desde perspectivas con características leve, parte por comprender que los límites entre disciplinas entran a un proceso de difuminación y mímesis de sus campos de acción, generando alianzas gnoseológicas, instrumentales y procedimentales que fomentan, amplifican y multiplican sus potenciales.

Acciones que apuntan a la generación de una arquitectura cuya tectónica va dando y ha dado cabida a los agenciamientos, que desde un abordaje interdisciplinario permiten permear por otros procesos, experiencias y efectos a la arquitectura para ir renunciando a sus características tectónicas. Una arquitectura que desde su generación y experiencia pueda ser capaz de asumir los procesos cambiantes de nuestra época, así, como "[...] con todas aquellas contingencias que hagan que el espacio sea compatible con todo lo que nos rodea” (Gausa et al, 2000, pág. 328).

\section{Autoría}

La primera autora ha conceptualizado, sustentado, diseñado la investigación y construido el primer, tercer y cuarto apartado. El segundo autor ha sustentado el segundo apartado. El tercer autor ha construido el segundo apartado e indagado sobre cada uno de los estudios de caso. 
Conflicto de intereses: Los autores declaran que no hay conflicto de intereses.

\section{Bibliografía}

Anders, V. et al. (2018). Etimología de ARQUITECTO. Recuperado de: http://etimologias.dechile.net/?arquitecto

Aparicio, J. M. (2000) El muro. Buenos Aires, Argentina: Librería Técnica.

Azara, P. (2005) Castillos en el aire. Barcelona, España: Editorial Gustavo Gili.

Azpiazu, Juan Ignacio. (2013) (Ed). Semper: el estilo en las artes técnicas y tectónicas, o, estética práctica y textos complementarios. Buenos Aires, Argentina: Azpiazu Ediciones.

Barba, J. (2018). Pabellón para la Serpentine Gallery 2006 por Rem Koolhaas y Cecil Balmond. Metalocus. Recuperado de https://www.metalocus.es/es/noticias/pabellon-para-la-serpentinegallery-2006-por-rem-koolhaas-y-cecil-balmond

Bauman, Z. (2004). Modernidad líquida. Ciudad de México, México: Fondo de Cultura Económica.

Benévolo, L. (2010). Historia de la arquitectura moderna. $8^{a}$ edición. Barcelona, España: Editorial Gustavo Gili.

Bohm, D. (2008). La totalidad y el orden complicado. 6a edición. Madrid, España: Editorial Kairos.

Brand, S. (1994). How Buildings Learn: What happens after they're built. Nueva York, Estados Unidos: Penguin Books.

Butragueño, B. (2015). Rem a los dos lados del espejo. Tesis doctoral. Universidad Politécnica de Madrid. ETS de Arquitectura de Madrid. Departamento de Ideación Gráfica Arquitectonica. Madrid, España.

Ferrater, C. y Ferrater, B. (2006). Sincronizar la geometría: paisaje, arquitectura y construcción. Barcelona, España: ACTAR.

Campo Baeza, A. (1999). La idea construida. La arquitectura a la luz de las palabras. Buenos Aires, Argentina: Universidad de Palermo.

Campo Baeza, A. (2003). Sustancia y circunstancia: memoria del curso 2002-2003 de las asignaturas proyectos arquitectónicos 4 y 5. Madrid, España: Mairea Libros.

Carabias, F. (2016). Conexión Mies SANAA. Sobre la intervención de Sanaa en el pabellón de Barcelona de Mies. Revista de Arquitectura, 21(30), 40-49. DOI: http://dx.doi.org/10.5354/0719-5427.2016.41354

Cirugeda, S. (2007). Situaciones urbanas. Barcelona, España: Editorial Tenov.

Conde, Y. (2000). Arquitectura de la indeterminación. Barcelona, España: Actar.

Corominas, J. (1985). Diccionario crítico etimológico Castellano e hispano. Tomo A-C. Madrid, España: Editorial Gredos.

ACE, 14. (4.2) CC BY-ND 3.0 ES | UPC Barcelona, España | Ámbitos dinámicos. De cómo la tectónica cede paso a los 
Corominas, J. (1985a). Diccionario crítico etimológico Castellano e hispano. Tomo C-F. Madrid, España: Editorial Gredos.

Dalí, S. (2004). Los cornudos del viejo arte moderno. Barcelona, España: Editorial Tusquets.

Deleuze, G. y Guattari, F. (2003). Mil mesetas. Capitalismo y Esquizofrenia. Traducción de José Vázquez Pérez con la colaboración de Umbelina Larraceleta, Valencia, España: Pre-textos.

Deleuze, G. y Guattari, F. (2010). Rizoma. (Introducción). Traducción de José Vázquez Pérez y Umbelina Larraceleta, Valencia, España: Pre-textos.

Frampton, K. (1999a). Estudios sobre cultura tectónica. Poéticas de la construcción en la Arquitectura de los siglos XIX y XX. Madrid, España: Akal.

Frampton, K. (1999). Rappel a l'ordre: The case for the Tectonic. Architectural design. 60: 19-25.

Galofaro, L. (2004). Artscape. El arte como aproximación al paisaje contemporáneo. Barcelona, España: Editorial Gustavo Gili.

Gausa, M. et al. (2000). Diccionario Metápolis de Arquitectura Avanzada. Barcelona, España: ACTAR.

Gausa, M. (2001). Arquitectura es (ahora) geografía. Otras "naturalezas" urbanas. Arquitectura: Revista del Colegio Oficial de Arquitectos de Madrid (COAM). 325, 72-81. Recuperado de http://www.coam.org/media/Default\%20Files/fundacion/biblioteca/revista-arquitectura-100/20002008/docs/revista-articulos/revista-arquitectura-2001-n325-pag72-81.pdf

Gómez de Silva, G. (2001). Breve diccionario etimológico de la lengua española. Ciudad de México, México: Fondo de Cultura Económica, 2001.

Guattari, F. (2004). Plan sobre el planeta: Capitalismo mundial integrado y revoluciones moleculares. Madrid, España: Traficantes de sueños.

Hansen, O. y Hansen, Z. (1961). The Open Form in Architecture-the Art of the Great Number. En CIAM "59 in Otterlo, Stuttgart: Karl Krämer Verlag.

Heredia, J. (2014). Dispositivos y/o agenciamientos. Contrastes. Revista Internacional de Filosofía, XIX(1), 83-101. Recuperado de https://www.uma.es/contrastes/pdfs/019/5-Juan Manuel Heredia.pdf

Ingels, B. (2009). Yes is more: an archicomic on architectural evolution. 2ª edición. Nueva York, Estados Unidos: Taschen.

Izuzquiza, I. (2003), Filosofía del presente. Una teoría de nuestro tiempo. Madrid, España: Editorial Alianza.

Jaque, A. (2013). Dulces arenas cotidianas. Madrid, España: Editorial Lugadero.

Koolhaas, R. y Mau, B. (1995). S, M, L, XL. Nueva York, Estados Unidos: Monacelli Press.1997.

Larsson, M. (2009). Tranforming Dunas into Architecture. TED Talks. Recuperado de http://www.ted.com/talks/magnus larsson turning dunes into architecture.html

ACE, 14 (1.2) CC BY-ND 3.0 ES | UPC Barcelona, España | Ámbitos dinámicos. De cómo la tectónica cede paso a los 
Lynn, G. (2004). (Ed). Folding in architecture. Chichester, Reino Unido: Wiley-Academy.

Machado, M. V. (2013). Desde la TRANSformación hacia la TRANSposición. Tesis doctoral. Universidad del Zulia. Facultad de Arquitectura y Diseño. Venezuela.

Machado, M. V. (2018). Del espaciar del espacio al mediar del medio. De lo funcional hacia lo performativo. HipoTesis Serie Numerada, 6, 101-122. Recuperado de http://hipotesis.eu/serienumerada/index.php/ojs/article/view/hipo6machado

Manaugh, G. Sand/Stone. (2009). BLDGBBLOG. Recuperado de http://www.bldgblog.com/2009/04/sandstone/

Morin, E. (2005). Introducción al pensamiento complejo. Barcelona, España: Editorial Gedisa

Montaner, J. M. (2002) Las formas del siglo XX. Barcelona, España: Gustavo Gili.

Montaner, J. M. (2008). Sistemas arquitectónicos contemporáneos. 2a edición. Barcelona, España: Gustavo Gili.

Montaner, J. M. (2013). Arquitectura y crítica. 3a ed. Barcelona, España: Gustavo Gili.

Montaner, J. M. (2014). Del diagrama a las experiencias, hacia una arquitectura de la acción. Barcelona, España: Gustavo Gili.

Nouvel, J., Baudrillar, J. (2003), Los objetos singulares. Madrid, España: Fondo de Cultura Económica.

Oxman, N. et al. (2014). Silk Pavilion: A Case Study in Fiber-based Digital Fabrication. En: FABRICATE Conference Proceedings. Gramazio, Kohler, Silke (Eds.) Ta Verla. 248-255. Recuperado de https://neri.media.mit.edu/assets/pdf/Conf FABRICATE ArticleOxmanLaucks.pdf

Price, C. y Littlewood, J. (1968). The Fun Palace. The Drama Review, TDR 12(3), 127-134. DOI: http://dx.doi.org/10.2307/1144360

Prigogine, I. (1998). El fin de las certidumbres. Santiago de Chile, Chile: Editorial Andrés Bello.

Saramago, J. (2001) Ensayo sobre la ceguera. Madrid, España: Alfaguara.

Semper, G. (2014). Escritos fundamentales de Gottfried Semper: el fuego y su protección. Antonio Armesto Aira (Ed.) Barcelona, España: Fundación Arquia.

Soriano, F. (2004) Sin tesis. Barcelona: Editorial Gustavo Gili.

Van Berkel, B. y Bos, C. (2002). Un Studio: Unfold. Roterdam, Paises Bajos: Nai Uitgevers Publishers.

Venturi, R. (2008). Complejidad y contradicción en la arquitectura. 2a edición. Barcelona: Editorial Gustavo Gili.

Walker, E. (2014). Una conversación con José Selgas y Lucía Cano. El Croquis. 171, 6-21.

Zaera-Polo, A. (2016). Ya bien entrado el siglo XXI ¿las arquitecturas del post-capitalism? El Croquis, 187, 252-287.

ACE, 14. (4.2) CC BY-ND 3.0 ES | UPC Barcelona, España | Ámbitos dinámicos. De cómo la tectónica cede paso a los 